\title{
Comparison Study of the Dynamic Loading Characteristics between Peat and Sand Based on its Physical Properties
}

\author{
Adnan Zainorabidin ${ }^{1, a}$, Siti Nurul Aini Zolkefle ${ }^{2, b^{*}}$, \\ Alvin John Lim Meng Siang ${ }^{3, c}$, Habib Musa Mohamad ${ }^{4, d}$ \\ and Siti Nooraiin Mohd Razali ${ }^{5, e}$ \\ 1,2,3,4,5Department of Infrastructures and Geomatic Engineering, \\ Faculty of Civil and Environmental Engineering \\ Universiti Tun Hussein Onn Malaysia, 86400 Batu Pahat, Johor, Malaysia \\ aadnanz@uthm.edu.my, bputri_aizlin@yahoo.com , calvinjlms@gmail.com , \\ dhabibmusa_mohamad@yahoo.com, ezahreenaiin@gmail.com
}

Keywords: Dynamic, Peat Soil, Sand

\begin{abstract}
Peat soils are challenging soils which are a problem for many geotechnical engineers especially in the design of shallow foundations and road constructions. The engineering properties of peat are dependent on the nature of its physical properties. Micro structural studies done on the soil shows that it consists of fibres which cause the soil to be highly compressible resulting in excessive settlement when they are subjected to moderate load increments or vibrations produce by traffic. In this paper, dynamic testing was done to approximately simulate traffic loading characteristics on peat taken from Parit Nipah and Pontian, Johor using a cyclic triaxial testing with $1 \mathrm{~Hz}$ loading frequency. The results were compared with soil that has a stiffer particulate nature such as sand. The comparison showed that the dynamic loading parameters of dynamic shear modulus and damping ratio of peat was dependent on the fiber content and was very much lower than that of well graded and uniform sands. This can be an important indication to understand the key parameter behaviour of peat that must be taken into account when designing and managing infrastructures on peat soils.
\end{abstract}

\section{Introduction}

The reactions of peat towards the road and highways in Malaysia have been of concern to most engineers since the definition of peat soil has been said as poorly, challenging, difficult accessibility and problematic soil [1]. Malaysia consists of three million hectares covered with peat which approximately about $8 \%$ of the land area of the country [2]. Peat soils were observed to be predominantly along the coastal area with the annual rate intensities of peaty soil predicted as $2 \mathrm{~cm}$ per year [3]. It has been agreed that the significant parameters in Geotechnical Engineering controlling the response of soil towards the cyclic loading are shear modulus and damping ratio [4]. These parameters must be determined to accurately measure their expected and required response towards earthquake shaking [5] and also for the design of geotechnical engineering problems [6]. The cyclic properties of peat that have been most substantially investigated in prior work are the variations of shear modulus and damping ratio with cyclic shear strain. Previous work identified in the literature on the performance of peat cyclic was associated with Kramer [7],[8]. Mercer Slough peat in Washington, [9], peat in Sherman Island, California [5], Montezuma Slough and Clifton Court peat [10], California Bay Delta [11], Bogota's Subsoil Peat [12] and Malaysia Peat [13]. Therefore, it is essential to find an alternative to improve the strength of soil since the dynamic characteristic study was introduced as one of the technique design methods. The main objectives of this study is to compare the results of shear modulus and damping ratio of peat soil and sand located in Johore, Malaysia using $1 \mathrm{~Hz}$ loading frequencies.

The increasing need for regional development has led engineers to find safe ways to construct the infrastructure of transportation on soft soils. Soft soil is not able to sustain external loads 
without having large deformations. In pavement engineering, highway or runway as an infrastructure, a pavement encompasses three important parts, namely traffic load, pavement and subgrade. Traffic load generated from tyre pressure of vehicle wheels on the surface of the pavement is important in the design and analysis in pertaining the problems that generally related to static and dynamic loading. The understanding of the static and dynamic behaviour of peat is still in its embryonic stage as compared to sand which has been well established in liquefaction analysis. However, as compared to sand, the cyclic triaxial testing indicated that the modulus reduction and damping behaviour of peat was significantly influenced by strain amplitude and effective confining pressure and was weakly influenced by loading frequency and over consolidation ratio [8].

Comparison of the behaviour of peat suggests a trend of response analysis indicated strong response at low frequencies with spectral shapes that needed more understanding. Traffic vibration is experienced by many people living alongside heavily trafficked roads, and there is a need to understand the nature of this problem so that the predictions of nuisance can be made and remedial treatments can be devised.

\section{Test Material and Method Approach}

The main objectives of this study is to compare the results of shear modulus and damping ratio of peat soil and sand located in Johore, Malaysia using $1 \mathrm{~Hz}$ loading frequencies. The index properties test and dynamic test have been performed to determine the characteristics and parameters required. All tests were conducted in the Research Centre for Soft Soil (RECESS) laboratory in Universiti Tun Hussein Onn Malaysia. For the testing of peat soil, the samples were taken from two different locations which are from Parit Nipah and Pontian, situated at Western Johore, Malaysia. The soil was obtained by firstly excavating the peat to a depth of 0.3 meters from the topsoil and pushing slowly a tube sampler with the size of $50 \mathrm{~mm}$ in diameter and $100 \mathrm{~mm}$ in height. The qualities of samples were maintained by ensuring the sharpness of the walls at the end of the tube facing the soil and waxed at both the end prevent the loss or gain of moisture.

In this research, the tube sampler taken from the site was carefully extruded and cautiously trimmed to a diameter of $50 \mathrm{~mm}$ and a height of $100 \mathrm{~mm}$ using a sharp knife and was quickly weighted to minimize the disturbance on the moisture content [14]. For triaxial testing, the specimen was enclosed in a high-density latex membrane and porous stones and filter papers were inserted at the ends of the specimen. The top cap and the bottom pedestal are fastened with two rubber-o-rings respectively, which seals the membrane to the top cap and the bottom pedestal. Then, the triaxial cell was assembled with the loading piston and the specimen is ready to be pressurized stage by stage. Fig. 1(a) illustrates the specimen setup for the cyclic triaxial test of peat.

For the sand samples, two types of sand which were obtained from Kahang, Johor were used for dynamic testing. These sands are classified as well graded (SW) and uniformly graded (SPu). The sand samples were formed using a cylindrical split mould placed on top of the triaxial pedestal base as shown in Fig. 1(b) with a size of $50 \mathrm{~mm}$ in diameter and $100 \mathrm{~mm}$ in height with a rubber membrane inserted in it. The undercompation method as described by [15] was adopted to prepare the samples as this method is known to minimize particle segregation during pouring. Just as the peat samples, porous stones were first placed at the base and at the top of the sample after compaction with $\mathrm{O}$ rings fastened at both ends. In order that the samples are stiff enough to be able to stand without the support of the split mould, a small negative back pressure was imposed on the sample using the back pressure control system. After the mould was removed, the diameter and height of the specimen were measured to the nearest $0.01 \mathrm{~mm}$. 


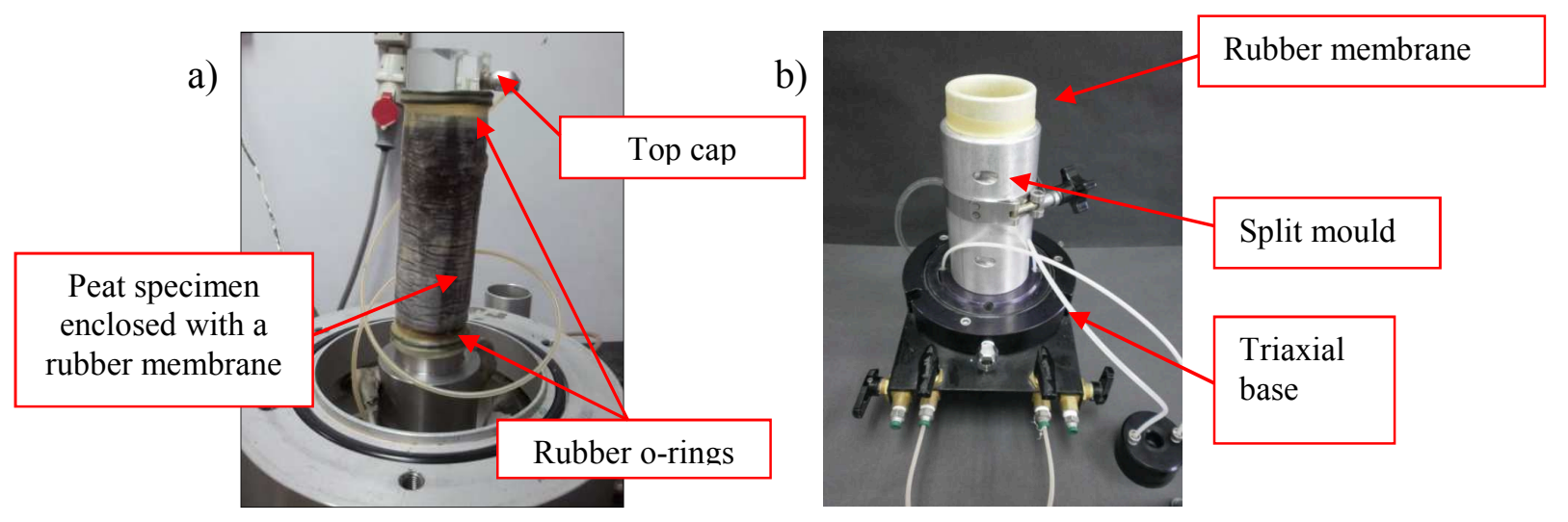

Fig. 1 Specimen Setup for Cyclic Triaxial Test on (a) peat and (b) sand

Undrained cyclic triaxial tests on fully saturated samples were used to study the dynamic characteristics of peat and sand. Anisotropic consolidation was used to specifically simulate stress conditions of a soil under asymmetric loading and at shallow depths [16]. This process was done by initially applying an all around confining pressure of $100 \mathrm{kPa}$, followed by an initial static axial stress $\left(\sigma_{\mathrm{i}}\right)$ which was always kept at half of the monotonic strength/peak deviator stress $\left(\sigma_{\mathrm{p}}\right)$ of the sample $\left(\sigma_{\mathrm{i}}=0.5 \sigma_{\mathrm{p}}\right)$.

\section{Research Results}

Index Properties of Peat The physical properties of the PNpt and POpt are shown in Table 1. The preliminary identification of the soil was made based on the index properties tests conducted on the peat soil sample. Peat was classified based on the degree of humification known as Von Post Scale and the organic and fibre content in the soil sample. The degree of humification test was done by based on the appearance of soil waster that is extruded when a sample of soil is squeezed in the hand.

Table 1 Physical Properties of Peat and Sand

\begin{tabular}{lllll}
\hline Parameters & PNpt & POpt & SW & SPu \\
\hline Moisture Content (\%) & 710.44 & 898.91 & - & - \\
Organic Content \%) & 78.77 & 76.55 & - & - \\
Fiber Content (\%) & 40.97 & 43.65 & - & - \\
Liquid Limit (\%) & 318 & 255 & - & - \\
Specific Gravity & 1.43 & 1.28 & - & - \\
Soil pH & 3.69 & 3.72 & 2.65 & 2.66 \\
Degree of Humification & H6 & H5 & - & - \\
& $($ Hemic) & (Hemic) & & \\
$\mathrm{D}_{10}$ & 0.0045 & 0.007 & 0.38 & 0.35 \\
Uniformity coefficient $\left(\mathrm{C}_{\mathrm{u}}\right)$ & 6.22 & 5.86 & 3.58 & 1.86 \\
\hline
\end{tabular}

Loss on ignition test has been conducted on the samples collected to obtain the organic content of the samples. From the table it can be concluded that the sample has very high value of loss of ignition and organic content. The value of liquid limit is high because the sample contains a lot of fibers which results in high water absorption capacity [17]. The physical properties of the sand samples are also shown in Table 1. The sands are completely different in terms of its particle size distribution where it is classified as well graded (SW) and uniformly graded ( $\mathrm{SPu}$ ) respectively. The difference in the sands particulate nature will help to show a more predictable difference in its dynamic properties. As compared to peat, both the samples showed similar uniformity coefficient 
$\left(\mathrm{C}_{\mathrm{u}}\right)$, which can be deemed classified as well graded soils. However, the particulate nature of peat is more importantly differentiated by the organic and fiber content of the soil.

Damping Ratio and Shear Modulus of Peat The cyclic or dynamic characteristics of soils are based on two important parameters of damping ratio (D) and the shear modulus (G). The cyclic parameters of $\mathrm{D}$ and $\mathrm{G}$ for peat soils are unpredictable and difficult to be tested. Recent investigations on dynamic soil properties explains that the importance of dynamic parameters is to evaluate the response and stability of surface soil layers [18]. In this paper, D and G were both calculated using the hysteresis loop as suggested in ASTM D3999-91. The behaviour of dynamic D and $G$ of peat soils was different due to its natural features and different percentages of natural contents. Fig. 2 displayed the results for both Parit Nipah peat (PNpt) and Pontian peat (POpt) on $1 \mathrm{~Hz}$ loading frequency with $\sigma^{6}=100 \mathrm{kPa}$. The peat with a higher fiber content that is represented by PNpt shows higher damping ratio and lower shear modulus values as an overall compared to POpt.
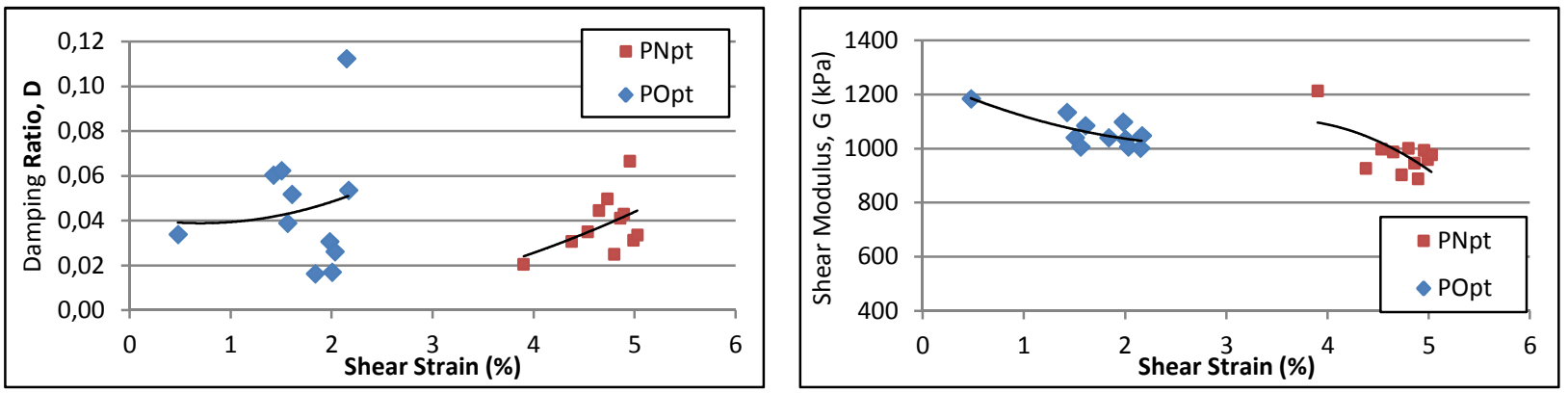

Fig 2. Damping Ratio and Shear Modulus of PNpt and POpt
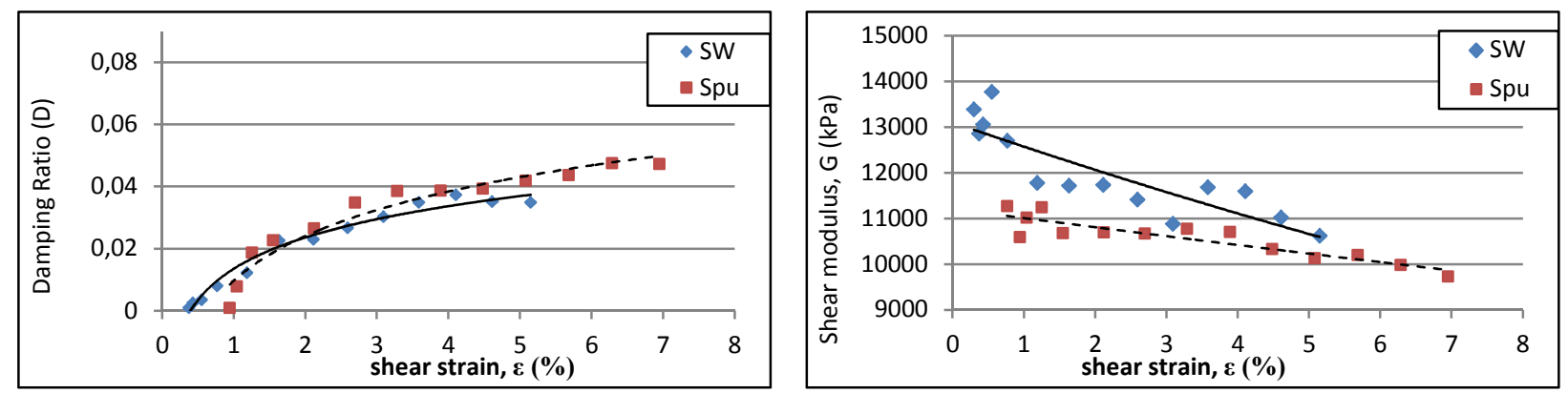

Fig. 3 Damping ratio and shear modulus of SW and SPu sand

Comparing to the sand samples however, the well graded and uniformly graded sands show that the shear modulus $(\mathrm{G})$ is very much higher than the peat samples as seen in Fig. 3 and a much lower value of the damping ratio as compared to the peat samples. The characteristics of the natural properties of sand are very much different from that of peat. Sand particle in nature is incompressible and the stiffness of the soil is dependent on the particle arrangement of the particles. Therefore, the results of the cyclic testing showed a more consistent reading of $D$ and $G$ for sand samples. This also explains that the well graded (SW) sand has higher values in $D$ and $G$ as compared to uniformly distributed sand ( $\mathrm{SPu}$ ). This is due to the better interlocking structure of the well graded sand than that of uniformly graded sand. The similarity of the results of both the peat and sand samples shows that the readings of damping ratio (D) increases and shear modulus (G) decreases respectively as the shear strain on the sample increases.

On the other hand, the inconsistencies of the readings of $\mathrm{D}$ and $\mathrm{G}$ on the peat soils are due to the high fiber content in the soil medium. The nature of its particulate structure of peat is the high content of fibers are compressible and it is high in water content which would result to a lower value in the shear modulus and a higher damping ratio. 


\section{Conclusion}

Peat soils are very challenging for geotechnical engineers to study and to construct structures on them. The dynamic characteristic of peat in terms of its damping ratio (D) and shear modulus (G) shows inconsistency in the results. As an overall, peat with a higher fiber content which is represented by PNpt shows higher damping ratio and lower shear modulus values as compared to lower fiber content of POpt. Such a study has not been found yet that would occur on peat samples. Comparative study with the well established dynamic behaviour of sand showed a different outcome. Sand is stiffer in nature and does not show any compressibility characteristics. Thus, the results are consistent and showed that the dynamic parameters are dependent on the particle arrangement of sand, resulting to higher $\mathrm{G}$ and a lower $\mathrm{D}$ value for well graded as compared to that of uniformly graded sand respectively. Compared to peat samples, the sand samples also show very much higher $\mathrm{G}$ values. However, the damping ratio of peat was slightly higher than that of sand.

\section{Acknowledgement}

This research is funded by the Ministry of Education under Fundamental Research Grants Scheme (FRGS, Vot 1224).

\section{References}

[1] A. Dehghanbanadaki, K. Ahmad and N. Ali: Influence of Natural Fillers On Shear Strength of Cement Treated Peat. Gradevinar, vol 65, no 7, (2013) p. 633-640

[2] J.M. Said and S.N.L. Taib: Peat Stabilization With Carbide Lime. UNIMAS E-Journal of Civil Engineering, vol 1, issue 1, (2009).

[3] H. Al-Ani, E. Oh and G. Chai: Characteristics Of Embedded Peat In Coastal Environments. International Journal of Geomate, Vol 5, No 1, (2013) p. 610-619.

[4] P. Kallioglou, T. Tika, G. Koninis, S. Papadopoulos and K. Pitilakis: Shear Modulus and Damping Ratio of Organic Soil. Geotech Geol Eng, Vol 27, (2009) p. 217-235.

[5] T.M. Wehling, R.W. Boulanger, L.F. Harder, JR. and M.W. Driller: Confinement and Disturbance Effects on Dynamic Properties of Fibrous Organic Soil. XV ICSMGE Satellite Conference On Lessons Learned From Recent Strong Earthquakes. (2001) p. 211-217.

[6] T.G. Sitharam, L. Govindaraju and A. Sridharan: Dynamic Properties and Liquefaction Potential of Soil. Current Science, Vol 87, No 10, (2004) p. 1370-1378.

[7] S.L. Kramer: Dynamic Response of Peat. Final Research Report, Research Project T9233, Task 28, (1996).

[8] S.L. Kramer: Dynamic Response of Mercer Slough Peat. Journal of Geotechnical and Geoenvironmental Engineering, vol 126, no 6, (2000) p. 504-510.

[9] R.W. Boulanger, R. Arulnathan, F.H.J. Leslie, R.A. Torres and M.W. Driller: Dynamic Properties Of Sherman Island Peat. Journal of Geotechnical And Geoenvironmental Engineering, vol 124, no 1, (1998) p. 12-20.

[10] T. Kishida, T. M. Wehling, R.W. Boulanger, M.W. Driller and K.H. Stokoe II: Dynamic Properties Of Highly Organic Soils From Montezuma Slough And Clifton Court. Journal Of Geotechnical And Geoenvironmental Engineering, Vol 135, no 4, (2009) p. 525-532.

[11] R. E.S. Moss and J. Hollenback: Seismic Response of Peaty Organic Soils as a Levee Foundation Material. Geo-Frontiers Conference Proceedings: Dallas, Tx, (2011).

[12] C.A. Moreno and E.E. Rodriguez: Dynamic Behaviour of Bogota's Subsoil Peat and Its Effect In Seismic Wave Propagation. $13^{\text {th }}$ World Conference on Earthquake Engineering, Canada, (2004).

[13] A. Zainorabidin: Static and Dynamic Characteristics of Peat with Macro and Micro Structure Perspective, PH.D Thesis in Civil Engineering, University of East London, (2011).

[14] Y. Duraisamy, B.K. Huat, and A.A. Aziz: Engineering Properties and Compressibility Behaviour of Tropical Peat Soil. American Journal of Applied Sciences, (2007) p. 768-773. 
[15] R.S. Ladd: Preparing Test Specimen using Undercompaction. Geotechnical Testing Journal, GTJODJ, 1(1), (1978) p. 16-23.

[16] M.T. Yilmaz, O. Pekcan, and B.S. Bakir: Undrained Cyclic Shear and Deformation Behaviour of Silt- Clay Mixtures of Adapazari, Turkey. Soil Dynamic and Earthquake Engineering, 24, (2004) p. 497-507.

[17] P.K. Kolay and M.P. Pui: Peat Stabilization using Gypsum and Fly Ash, UNIMAS E-Journal of Civil Engineering, Vol 1, issue 2, (2010).

[18] M.E. Raghunandan and A. Juneja: Behaviour of Soil Under Cyclic Loading. Indian Geotechnical Conference, IGS Mumbai Chapter \& IIT Bombay, (2010) p. 195-198 